\title{
Evaluation of lugol solution used for counting rumen ciliates
}

\author{
Marta D'Agosto ${ }^{1}$ \\ Maria Elisa Carneiro ${ }^{2}$
}

\begin{abstract}
The present study proposes a modification of the technique described by PURSER \& MOIR (1959) for the quantitative evaluation of rumen ciliate based on an adaptation described by DEHORITY (1984). The modifying process includes: the replacement of two drops of brilliant green dye, for at least four hours, by three drops of lugol solution, for at least 15 minutes. It was made a comparative evaluation of these stainings. It was concluded that lugol solution can replace the brilliant green dye showing the following advantages: staining time reduction and subsequent speeding of sample processing; evidence of skeletal plates of entodiniomorphs making its identification easier; improved observation of small ciliates and inconspicuous structures; improved total counting and generic identification of the ciliates.

KEY WORDS. Rumen ciliate, quantitative evaluation, lugol solution, technique
\end{abstract}

Among the techniques found in the literature for the quantitative evaluation of rumen ciliates are the one mentioned by OGIMOTO \& IMAI (1981) which uses a plankton counting slide, the Fuchs-Rosenthal and the Sedgewick-Rafter counting chamber. DEHORITY (1984) described an adaptation of the procedure proposed by PURSER \& MOIR (1959), using the Sedgewick-Rafter counting chamber. In order to improve the observation of ciliates and reduce the time of sample processing, the present work proposes the replacement of the brilliant green dye used by DEHORITY (1984) by the lugol solution. It also presents a comparison between these procedures.

\section{MATERIAL AND METHODS}

Thirty samples of rumen contents were obtained from rumen-fistulate crossbred Holstein Friesian-Zebu cow. Each sample consisted of approximately 20 $\mathrm{cm}^{3}$ of rumen content taken from the center of the rumen mass to which were added $20 \mathrm{ml}$ of rumen fluid obtained by aspiration. These $40 \mathrm{ml}$ were fixed in an equal volume of $18.5 \%$ formalin and processed according to DEHORITY (1984). It involved the usage of $1 \mathrm{ml}$ subsamples of the rumen content stained with two drops of brilliant green dye for at least four hours and subsequent dilution in $9 \mathrm{ml}$ of $30 \%$ glycerol. The differential counting of the ciliates was performed twice using a Sedgewick-Rafter counting chamber with $1 \mathrm{ml}$ of the diluted subsample. In another

1) Departamento de Zoologia, Instituto de Ciências Biológicas, Universidade Federal de Juiz de Fora. 36036-330 Juiz de Fora, Minas Gerais, Brasil.

E-mail: dagosto@icb.ufj.br

2) Departamento de Parasitologia Animal, Instituto de Biologia, Universidade Federal Rural do Rio de Janeiro. 23851-970 Seropédica, Rio de Janeiro, Brasil. 


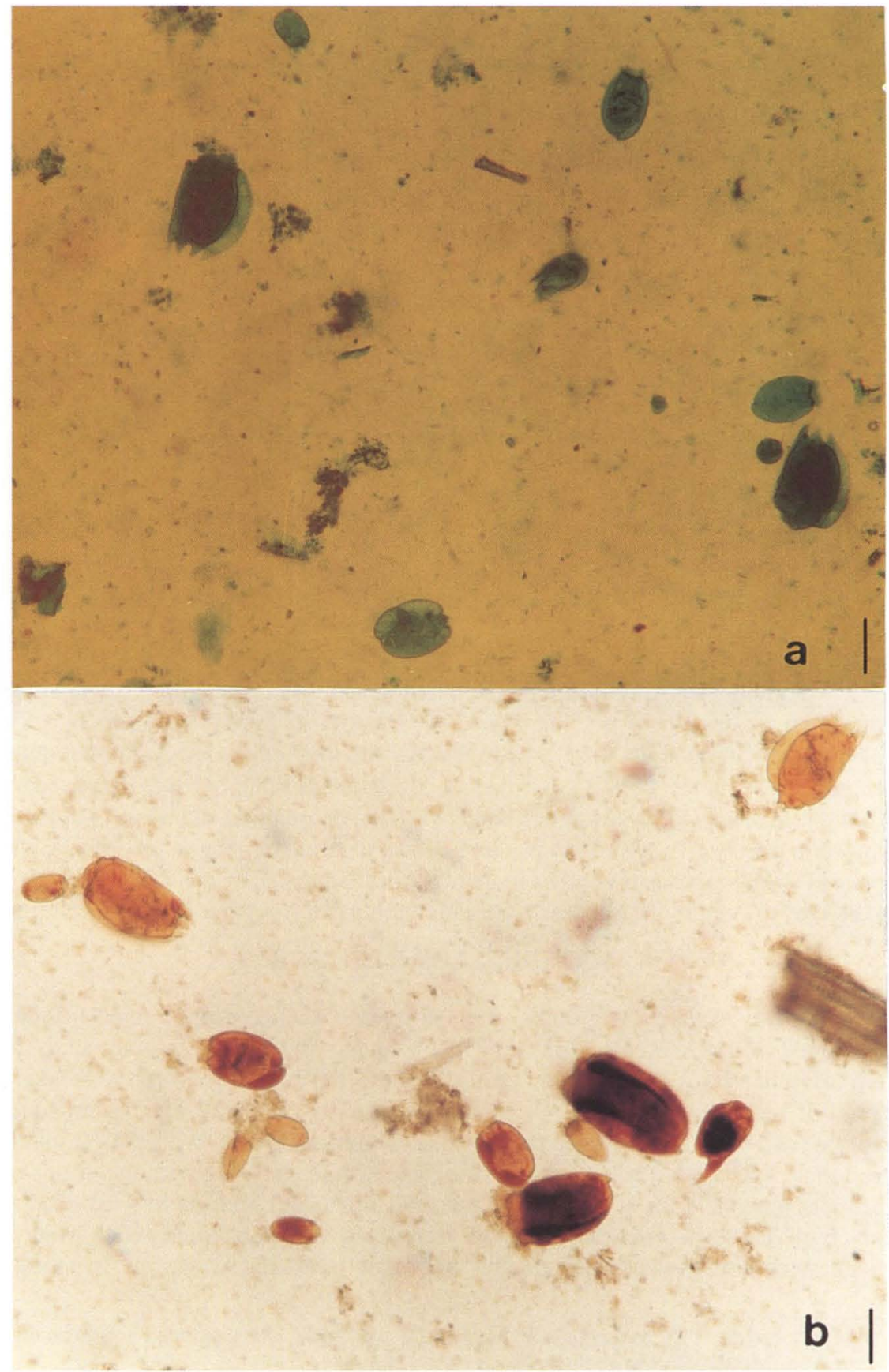

Fig. 1. Comparative aspects of ciliates observed in the rumen content stained with brilliant green dye (a) and lugol solution (b). Scale bar $=10 \mu \mathrm{m}$.

Revta bras. Zool. 16 (3): 725 - 729, 1999 
counting series, performed by the same person, the following adaptation was introduced: two drops of brilliant green dye were replaced by three drops of lugol solution for at least 15 minutes before the counting. After the staining, the glycerol was added. The data were analysed statistically by analysis of variance followed by the $5 \%$ Tukey test.

\section{RESULTS AND DISCUSSION}

The following genera of rumen ciliate have been identified and quantified: Entodinium Stein, 1859, Isotricha Stein, 1859, Dasytricha Schuberg, 1888, Charonina Strand, 1928, Eodinium Kofoid \& MacLennan, 1932, Eremoplastron Kofoid \& MacLennan, 1932, Polyplastron Dogiel, 1927, Diploplastron Kofoid \& MacLennan, 1932 e Ostracodinium Dogiel, 1927. The last three ones were analysed together and refered to as $\mathrm{P}+\mathrm{D}+\mathrm{O}$.

The total numbers of ciliates reported after staining with brilliant green and lugol solution were $295,346.66$ and $331,173.34$, respectively. The results of the differential counting of the ciliates using brilliant green and lugol solution with the respective average and percentage values are shown in table I. The results expressed the number of ciliates per milliliter of rumen content. The Entodinium, Isotricha, Dasytricha, Charonina and Eodinium values as well as the total values differed significantly between the treatments.

Figure 1 presents comparative aspects of ciliates observed in the rumen content stained with brilliant green dye and lugol solution.

The improved observation of ciliates using the lugol solution seems to be responsible for the significant difference observed in the total values in some of the genera (Tab. I). Besides, this procedure reduces the staining time and the subsequent speeding of sample processing. For enhancing ciliary structures, this staining significantly favoured the identification and counting of small ciliates showing more delicate structure such as in the genus Charonina.

Table I. Means, percentage and total numbers of ciliates of sampled rumen contents (number of ciliates per rumen content) stained with brilliant green dye and lugol solution.

\begin{tabular}{lrrrrr}
\hline \multirow{2}{*}{ Ciliates } & \multicolumn{2}{c}{ Brilliant green } & & \multicolumn{2}{c}{ Lugol solution } \\
\cline { 2 - 3 } \cline { 5 - 6 } \cline { 5 - 6 } & \multicolumn{1}{c}{$\mathrm{X}$} & \multicolumn{1}{c}{$\%$} & & $\mathrm{X}$ & $\%$ \\
\hline Entodinium & $254,493.33 \mathrm{a}$ & 86.17 & & $279,013.33 \mathrm{~b}$ & 84.25 \\
Isotricha & $5,240.00 \mathrm{a}$ & 1.77 & & $6,666.67 \mathrm{~b}$ & 2.01 \\
Dasystricha & $280.00 \mathrm{a}$ & 0.09 & & $586.67 \mathrm{~b}$ & 0.18 \\
Charonina & $7,413.33 \mathrm{a}$ & 2.51 & & $14,826.67 \mathrm{~b}$ & 4.48 \\
Diplodinium & $9,400.00$ & 3.18 & & $8,693.33 \mathrm{~b}$ & 2.63 \\
Eodinium & $6,373.33 \mathrm{a}$ & 2.16 & & $8,600.00 \mathrm{~b}$ & 2.60 \\
Eremoplastron & $3,240.00$ & 1.10 & & $3,346.67$ & 1.01 \\
$\mathrm{P}+\mathrm{D}+\mathrm{O}^{*}$ & $8,906.67$ & 3.02 & & $9,440.00$ & 2.85 \\
\hline Total & $295,346.66 \mathrm{a}$ & 100.00 & & $331.173 .34 \mathrm{~b}$ & 100.00
\end{tabular}

${ }^{*}$ ) Means in the same row followed by different letters are significantly different at $\mathrm{P}<0.05$; $(\mathrm{P}+\mathrm{D}+\mathrm{O})$ Polyplastron + Diploplastron + Ostracodinium; $\mathrm{N}=30$. 


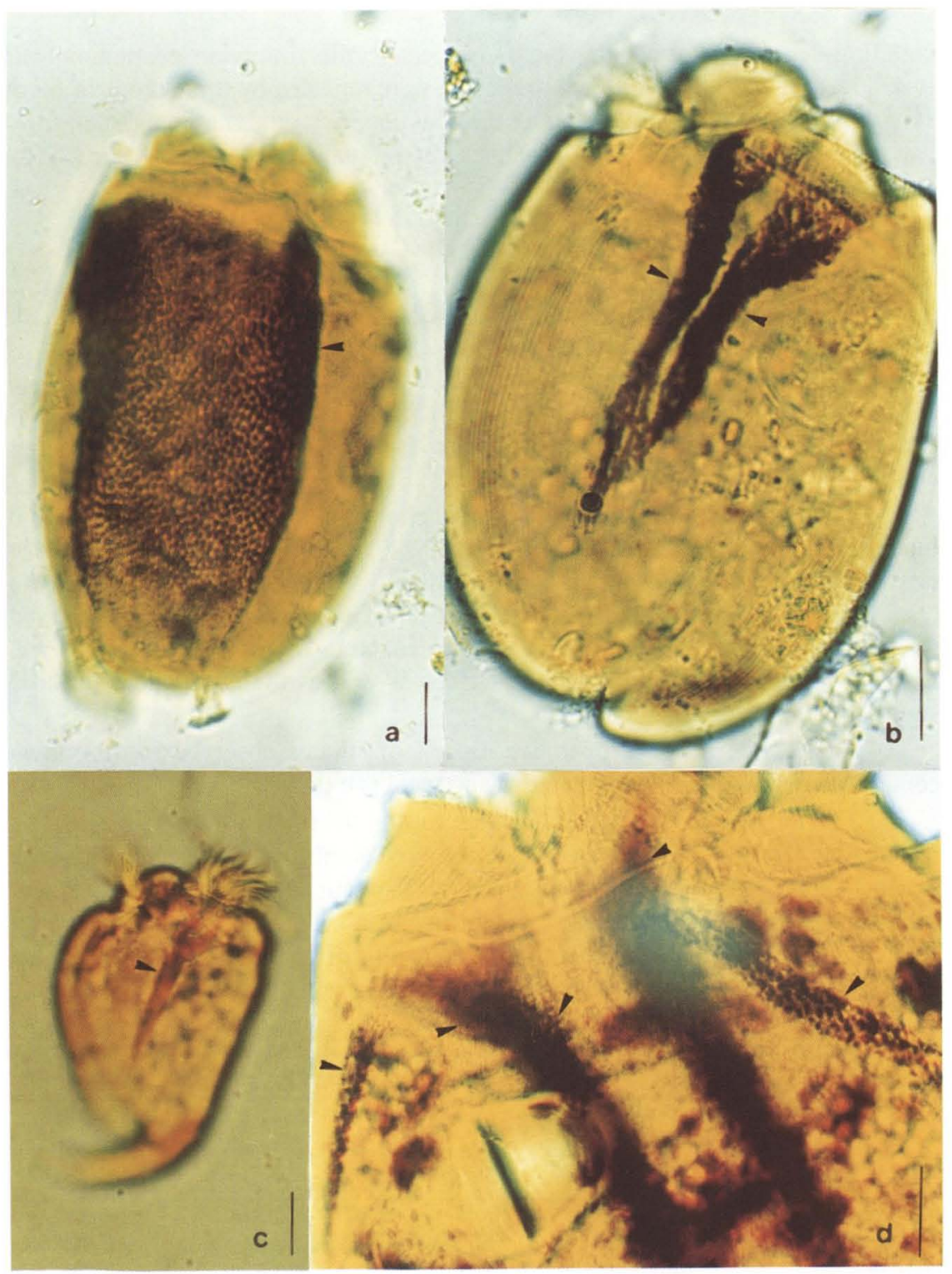

Fig. 2. Skeletal plates (arrows) of entodiniomorphs stained by lugol solution. Ostracodinium sp. (a), Diploplastron sp. (b), Eremoplastron sp. (c) and Polyplastron sp. (d). Scale bar $=10$ $\mu \mathrm{m}$.

It is shown the skeletal plates of large entodiniomorphs of the subfamily Diplodiinae (Fig. 2) which acquire a brown-redish staining when in contact with the lugol solution, owing to their polysaccharide nature. According to D'AGOSTO 
\& SANTA-RosA (1994) this observation is not possible with Feulgen's reaction or silver impregnation's technique.

\section{CONCLUSIONS}

Based on the results presented, it was concluded that the lugol solution can replace the brilliant green dye showing the following advantages: 1) staining time reduction and subsequent speeding of sample processing; 2 ) improved evidence of ciliates and facility for material reading; 3 ) improved observation of small ciliates and inconspicuous structures such as in Charonina sp.; 4) evidence of skeletal plates of entodiniomorphs, easing its identification; 5) improved total counting and generic identification of ciliates.

ACKNOWLEDGEMENT. We are grateful to Fundação de Amparao à Pesquisa de Minas Gerais (FAPEMIG) by the support.

\section{REFERENCES}

DEHORITY, B.A. 1984. Evaluation of subsampling and fixation procedures used for counting rumen protozoa. Appl. Environ. Microbiol. 48: 182-185.

D’Agosto, M. \& M.R. DE SANTA Rosa. 1994. Aspectos morfológicos de ciliados do rúmen (Entodiniomorphida, Ophryoscolecidae) revelados pelas técnicas do protargol e da reação de Feulgen. Revta bras. Zool. 11: 215-225.

Ogimoto, K. \& S. Imai. 1981. Atlas of Rumen Microbiology. Tokyo, Japan Scientific Societies Press, VII+231p.

PURSER, D.B. \& R.J. MoIR. 1959. Ruminal flora studies in the sheep.IX. The effect of $\mathrm{pH}$ on the ciliate population of the rumen in vivo. Aust. Jour. Agric. Res. 10: $555-564$.

Recebido em 13.I.1998; aceito em 19.VII.1999 